This article is accepted for publication in Convergence: The International Journal of Research into New Media Technologies.

\title{
The Mediated Festival: Live Music as Trigger of Music Streaming and Social Media Engagement
}

\author{
Anne Danielsen and Yngvar Kjus \\ (Department of Musicology) University of Oslo, Norway
}

Corresponding author:

Anne Danielsen

Department of Musicology

University of Oslo

Box 1017 Blindern

NO-0315 Oslo, Norway

Email: anne.danielsen@imv.uio.no

Tel: $+4722854751 /+4748214002$

Fax: +4722854763

\section{Funding}

This work was supported by the Research Council of Norway via the Clouds and Concerts research project [grant number 205265]. 


\begin{abstract}
Live music events are increasingly saturated with and mediated via the online and mobile devices of the audience. This article explores patterns in this media use surrounding the Øya festival in Norway and focuses in particular on music streaming and social media activity. It presents statistical analysis of listening sessions via the streaming service Wimp and social interactions via the micro-blogging platform Twitter. The juxtaposition of these unique access points allows the analysis to explore the impact of physical live concerts on the digital music experience. It also enables a nuanced examination of how the festival audience responds to different artist segments, from international headliners to local acts. One key finding is that local artists that are positively evaluated via Twitter have the greatest boost in subsequent music streaming. The article argues that in-depth studies of the intersection of live and mediated music are essential to understanding the encounter between artists and audiences that is facilitated by contemporary live music events.
\end{abstract}

\title{
Keywords
}

Live music, festival, social media, Twitter, mediatisation, streaming, participatory culture, digital fandom

\section{Introduction}

The live music scene and the record industry have both evolved extensively over the 2000 s, as demonstrated by the growth in music festivals (Robinson, 2015) and various online music services (Wikstrøm, 2013). At the same time, the relationship between these musical domains (the live and the recorded) has also changed, with ramifications for artists and audiences alike. The overarching objective of this article is to explore and specify patterns of music streaming and social media usage surrounding a music festival. More specifically, we ask what the effects of live performance actually are on online audience activity, and whether different artist segments exhibit different response patterns. In so doing we address the ways in which concerts trigger artist exposure and record listening in an era when audience members can share opinions via social media and access the recordings of whichever artist they want via streaming services. 
The live event to be engaged here is the Øya festival, which since its modest start in Oslo in 1999 has become the largest music festival in Norway. It takes place over four days during the second week of August and has about 16000 daily visitors. Around 80 bands play on four stages, and more than 40000 unique visitors usually attend one or more days of the festival (see also oyafestivalen.com). The festival has an indie rock profile, but also features genres like electronica, rap, metal and soul. It refers to itself as a boutique festival and is one of the several large Nordic popular music festivals, also including Roskilde and Hultsfred, with a significant international profile. These festivals consistently present international and local headliners, as well as smaller local artists. Moreover, they feature a high number of medium renowned international artists - that is, acts that are not particularly well known to the local audience. Even as the Nordic audience in this way enjoys a substantial supply of live concerts, its access to recorded music online is also high. Already in 2008, approximately 85 percent of Norwegian households had access to the Internet (Statistics Norway, 2016), and in 2012, revenues from digital formats outpaced sales of physical formats (IFPI Norway, 2015: 25). In fact, digital media accounted for 86 percent of Norwegian music sales in 2014, as opposed to only 32 percent of global sales (IFPI, 2015). Streaming services such as Spotify and Wimp (now Tidal) have now become the dominant form of music distribution in the Nordic countries, offering access to vast archives of recordings in return for advertising exposure or subscription fees. Norwegians have also embraced social media to a staggering extent, with more than half of the total population on Facebook and about one in five with a Twitter account (see Aalen, 2015). Norway is therefore well suited to an exploration of emerging patterns in music mediation. Using the live concerts at Øya in 2012 as our point of departure, then, we will examine related music streaming in Wimp and social interaction via Twitter, focusing in particular on the reception of local versus international, and headlining versus small/medium, artists.

We will start by reviewing the relevant literature and research regarding the role of live music in the digital age, zooming in on festivals and related media use. We will then present the methods of the study, including the ways in which we have accessed, processed and aligned quantitative data from different sources in order to provide new access points to the experiences and activities of the contemporary festival audience. Ultimately, we will present and discuss our findings. The article argues that a successful concert is a unique opportunity for local, smaller 
artists to generate activity in streaming services and social media. Generally, we demonstrate the ways in which a music festival today extends far beyond the here and now of the actual concerts, pointing to the close relationship between the domains of live and recorded music in our time.

\section{Live music in the digital age}

In an era when recorded music is available anywhere at any time, one might expect that live music would become less important. According to Simon Frith (2007), in fact, this was how the story of the live music business was told, until recently, and for good reason. First of all, following upon Baumol and Bowen's classic study (1966), economists have long tended to assume that live music would not improve worker productivity in the ways that mass entertainment media could. Secondly, one might well expect that job opportunities for live musicians would decline in proportion to the general domestication of musical activity and increase in the use of recorded music (see, for example, Frith, 1987; Sanjek and Sanjek, 1991). On the contrary, however, it appears that the interest in, status of and simply level of activity within the domain of live music have all increased in the midst of ubiquitous recorded music. One reason may be that live music has become perceived as a unique and rare musical experience-something that we expect to be particularly intense and surprising, or, in short, to stand out from our everyday listening (Kjus and Danielsen, 2014).

Relatedly, the economic viability of the live scene has increased as recorded-music revenue has decreased. According to Simon Frith, already in 2007 there was evidence that live music in the UK was one of the most buoyant areas of the musical economy (Frith, 2007), and UK festivals indeed seem to continue to grow (Brennan and Webster, 2010). Likewise, sources from the Nordic countries demonstrate economic growth in the live music sector over the last few decades (Kavli and Sjøvold, 2015; Steinkellner, 2015; Taule, 2010; Vaage, 2013). In addition, previous research indicates other positive correlations between the digital distribution of music and activity in the field of live music. Focusing in particular on the pop music festival, Robinson claims that 'the increased capacity for free listening has benefited the festival sector, and explains why, at the time of writing, live music revenues are almost double the revenues for recorded music' (2015: 47). Mortimer and colleagues (2012), investigating the effect of file sharing on live concert performances from 1995 to 2004, showed that while this activity reduced album sales 
significantly, particularly for major artists, the quantity of concert events grew after the arrival of Napster in 1999, in turn increasing the total revenue from live music significantly. Interestingly, these researchers also examined variation in this trend across artist segments and found that the concert revenues of smaller, more obscure bands increased more than those of larger bands after the onset of file sharing, suggesting that the broad redistribution of recorded music made possible by file sharing boosted the general awareness of smaller bands by making their music available from more sources and at a much lower cost (or for free, in the case of illegal file sharing). Their study provided broad support for their basic hypothesis that there is a complementary relationship between live and digitally distributed recorded music.

\section{Festivalisation and the role of music at music festivals}

The most rapidly growing area of live music has occurred in relation to festivals, for several reasons. As Frith (2007) points out, festivals attract huge audiences at lower cost than singlestanding concerts (Frith, 2007: 4). Festivals also seem to be an effective means of succeeding in the economy of attention within the music industry. Research from the Clouds and Concerts project in Norway, for example, shows that the streaming of festival artists increased by 40 percent in the festival period, compared to the control weeks (Maasø, 2016).

The increase in festivals has led researchers to refer to the general trend of festivalisation (Bennett, Taylor and Woodward, 2014), not only in the field of music but also in other sectors as well. ${ }^{1}$ Bennett and colleagues propose that festivals are a response to the general trend towards fragmentation and pluralisation in the area of culture, 'communicating something meaningful about identity, community, locality and belonging' (Bennett et al., 2014: 1). McKay argues along the same lines: 'In a digital era the motivation for the social gathering of the festival may be in part as compensation for the pervasive atomised and privatised experience of contemporary media and technology' (McKay, 2015: 4). Another important motivation for attending a festival seems to be the way in which it creates a space that stands out from everyday life. As Gibson and Conell put it, 'Most festivals create ... a time and space of celebration, a site of convergence

\footnotetext{
${ }^{1}$ According to a study of Australian festivals by Gibson and Conell (2007), in fact, fewer than 10 percent the festivals they studied were music oriented.
} 
separate from everyday routines, experiences and meanings - ephemeral communities in place and time' (Gibson and Conell, 2012: 4). McKay also emphasises the temporarily heightened space-time that a festival creates, and the related utopian desire of 'envisioning and crafting another, better world' (McKay, 2015: 4).

One might assume that music is a main reason for attending a music festival, but several studies have instead foregrounded the social aspect, which tends to increase in importance at camping festivals, where the audience actually lives for a time within the festival area (Fonarow, 2006). Likewise, Bowen and Daniels (2005), in their study of the motivations for attending festivals, found that music did not necessarily matter to those attending a music festival.

As Hesmondhalgh points out, however, there is not necessarily a contradiction between the social and aesthetic aspects of the live music experience-sharing an aesthetic experience at a concert is both about the music and about one's neighbors or the collective (Hesmondhalgh, 2013: 106). At a 'non-camping' festival like Øya, though, music is important—unlike a camping festival such as Roskilde, for example, which allows for considerable pre-festival partying (the camping sites open four days prior to the main program), the Øya festival starts with the first concert and ends with the last one. As Stone (2009) points out, for this type of festival, the 'lineup is everything' (Stone, 2009) - the program is usually carefully curated to meet the expectations of the audience members, who want both to see their 'entire record collection in one weekend' (Stone, 2009) and to be updated on what is new within the genres covered by the festival.

At the Øya festival, the program is carefully curated and contains a mix of new and established artists, as well as local and international acts. According to Øya's own audience survey, music and the selection of artists are the main reasons for attending the festival (Comte Bureau, 2012). It is reasonable, then, that the present study has a particular focus on the ways in which Øyа, as a music festival directed towards music, generates music-related activity on digital platforms. Apart from the general increase in the music streaming of festival artists reported by Maasø (2016; see also next section), research in this area is lacking; to our knowledge, there are no existing studies that examine the effect of a festival performance upon different segments of artists (local versus international, small or medium artists versus headliners). In addition, the potential effect of the quality of the performance at the festival upon activity on digital platforms 
such as social media and music-streaming services remains to be investigated.

\section{The mediated festival}

As pointed out above, music and media are now deeply intermingled in the domain of live music. Various online resources and activities, such as festival forums, music streaming of festival artists and festival-related content in social media, have become the immediate surroundings of a festival - the contemporary mediated festival, that is, stretches far beyond its physical and temporal limitations (the here and now of the actual concert and the festival venue) into a virtual realm. Using Hesmondhalgh's terminology (2013: 86), we might say that the music festival has grown from a mainly co-present form of social publicness to also include mediated forms of social publicness at various social networking sites. Contrary to pre-social media times, then, when there was a clearer line between co-present and mediated aspects (for example, broadcasts), the mediated festival is surrounded by new forms of media and subject to a heightened level of mediated online publicness, making the dividing line between co-present and mediated aspects of the festival less clear.

A related perspective on the unprecedented media situation surrounding live music events is what Wikstrøm has described as the new connectivity of the audience (Wikstrøm, 2009: 5-6). This connectivity is largely facilitated by social media, which allows for direct real-time communication during the event, and for, in the words of Baym, the personalising of 'an otherwise anonymous group' (2013: 224). In relation to the live music event, this means that the audience may now encompass fans that are not physically present at the event.

Generally, the interplay between live music events and the media platforms surrounding them seems to have fresh momentum with the new internet-based media and associated increase in participatory culture (Jenkins, 2006). This increase is premised on several factors, including the vast amount of information on the Internet, the availability of such information and the new conditions for simultaneity between the festival event, media activity and access to recorded music. Events have gained greater significance in the media landscape thanks to these enhanced opportunities for real-time communication in online media, providing, according to Hitzler and colleagues (2013), a framework for action through which emotional as well as mental affiliations 
can be constituted. In other words, in our era, events seem to provide a framework for action in the media landscape, working as attractors for attention and communication. Events may, for example, provide a structure or filter in terms of the abundance of music available in musicstreaming services (Maasø, 2016).

Writing on extended liveness in television, Ytreberg, in a study of Pop Idol and Big Brother, demonstrates how the broadcast media industry exploits live audience participation via digital return channels for the purposes of revenue, competitive edge and strategic expansion (Ytreberg, 2009). In the field of music, this new situation brings great topicality to studies that focus on the interplay between live music events, social media and online use of recorded music, yet such studies are scarce. One exception is Morey and colleagues, who explore the ways in which festivalgoers tend to 'both consume and produce - co-create - the festival experience' (Morey et al., 2014: 251) on dedicated festival websites and forums. The focus of these scholars is on how meanings and identities of festivals and festivalgoers alike are multiplied and extended through such activities, and like Ytreberg, they are concerned with the 'hidden' commercial aspects of such online extensions of the festival.

However, as Robinson points out, audience participation has also become important to the festival, adding value to the event in both economic and social terms: 'The principles of audience access and audience agency have become central to the festival identities, principles that are championed and disseminated through websites, social media and press releases throughout the year. As a natural side effect of this process, the status of the audience member and their contributions to the celebration are raised up' (Robinson, 2015: 175). Importantly, much of the mediatised activity surrounding the festival has no direct commercial objective but instead is user-generated and disseminated through ordinary channels for online communication and music listening - that is, channels not facilitated by the professional apparatus surrounding the event.

The use of mobile phones has become increasingly important to the 'extended' festival experience. In Lucy Bennett's (2014) study of the fan community of Tori Amos, Bennett examines texting and tweeting and other forms of mobile phone use at live events that are directed towards a fan audience that is not physically present. Bennett looks at what is gained or lost in the incorporation of online social platforms into the live experience and concludes that media engagement often disrupts the 'flow' experience of the fans who are physically present, 
while at the same time delivering a great amount of pleasure to those who are not present. The same ambivalence regarding mobile phone use is also discussed in an article on how the audience uses their mobile devices to prepare and process, document and communicate the event on online platforms before, during and after it (Kjus and Danielsen, 2014). ${ }^{2}$

In this article we report on activity on the microblogging platform Twitter and the streaming service Wimp that surrounded the Øya festival in 2012. We focus on Twitter communication at the macro level (Bruns and Moe, 2013) — that is, tweets hashtagged with Øyarelevant tags. Hashtags are commonly used to mark a tweet as relevant to a specific topic and have the potential to reach beyond the followers of the individual sender, because they can be tracked by any Twitter user. This form of communication is generally exploited to broaden the communicative process and increase visibility, leading Bruns and Moe to claim that 'tweeting to a topical hashtag resembles a speech at a public gathering' (2013: 18). Accordingly, the Twitter audience linked to a particular hashtag can be seen as a form of ad hoc public, rapidly forming and dissolving in turn (Bruns and Moe, 2013: 20). ${ }^{3}$ Bennett (2012) finds that tweeting and texting is used to broaden the fan community at live concerts and include fans that are not present at the event, for example by tweeting the set-list of the concert or commenting on the performance on stage. Also Jamison-Powell and colleagues (2014) found widespread use of Twitter among the audience during live music concerts. All this resonates well with research into the Twitter use that surrounds political election campaigns, which also points towards spikes in tweeting as representative of an immediate response to an event (in that case, events in the mainstream media; Larsson and Moe, 2012).

As pointed out above, research from the Clouds and Concerts project using data from the Norwegian streaming service Wimp has shown that performing at a festival generated an overall 40 percent increase in music streaming for the festival artists during the festival period. This is the so-called festival effect (Maasø, 2016). However, we do not yet know what the festival effect

\footnotetext{
${ }^{2}$ The article is based on focus-group interviews with ninety-one participants at the Øya festival during the years 2010-2013 that were conducted by the abovementioned Clouds and Concerts project.

${ }^{3}$ For celebrities, as well, the meso-level (that is, followee to followers) works as one-to-many communication (Bruns and Moe, 2013: 25-26) due to their different follower structure, that is, a large number of followers with no personal relations to the followee.
} 
is for different artist segments. Nor do we know whether the fact that the performance happens is enough in itself to generate activity on digital platforms after the event, or whether, in addition, the way in which it happens - that is, the qualities the performance - is important as well. Put differently, how does an event in physical space connect with exposure and listening in mediated space?

\section{Material and methods}

As indicated above, we wanted to investigate the effect of a festival performance upon music streaming and Twitter use for different artist segments along two axes: local versus international artists, and small and medium artists versus headliners. We expected that these different artist segments would display different patterns for streaming and Twitter. We also wanted to compare streaming after the concert (post-event streaming) for artists with a successful festival performance versus those with a neutral or not particularly notable performance.

Although our study was carried out in Norway, a vanguard of online music media, it applies to similar developments in other parts of the world as well. For example, there are now approximately 968 million users of streaming services worldwide (IFPI, 2016: 22), and the number of Twitter users has surpassed 310 million.

\section{Selection of artists}

We decided to focus on medium-sized artists and headliners, respectively, because they command a certain volume of streaming, whereas streaming numbers for smaller artists are susceptible to outliers - even very small changes in nominal streaming give rise to strong relative effects. The headliners and medium-sized artists were identified using the Øya festival's own categorisation, as displayed on its festival poster (see figure 1). 


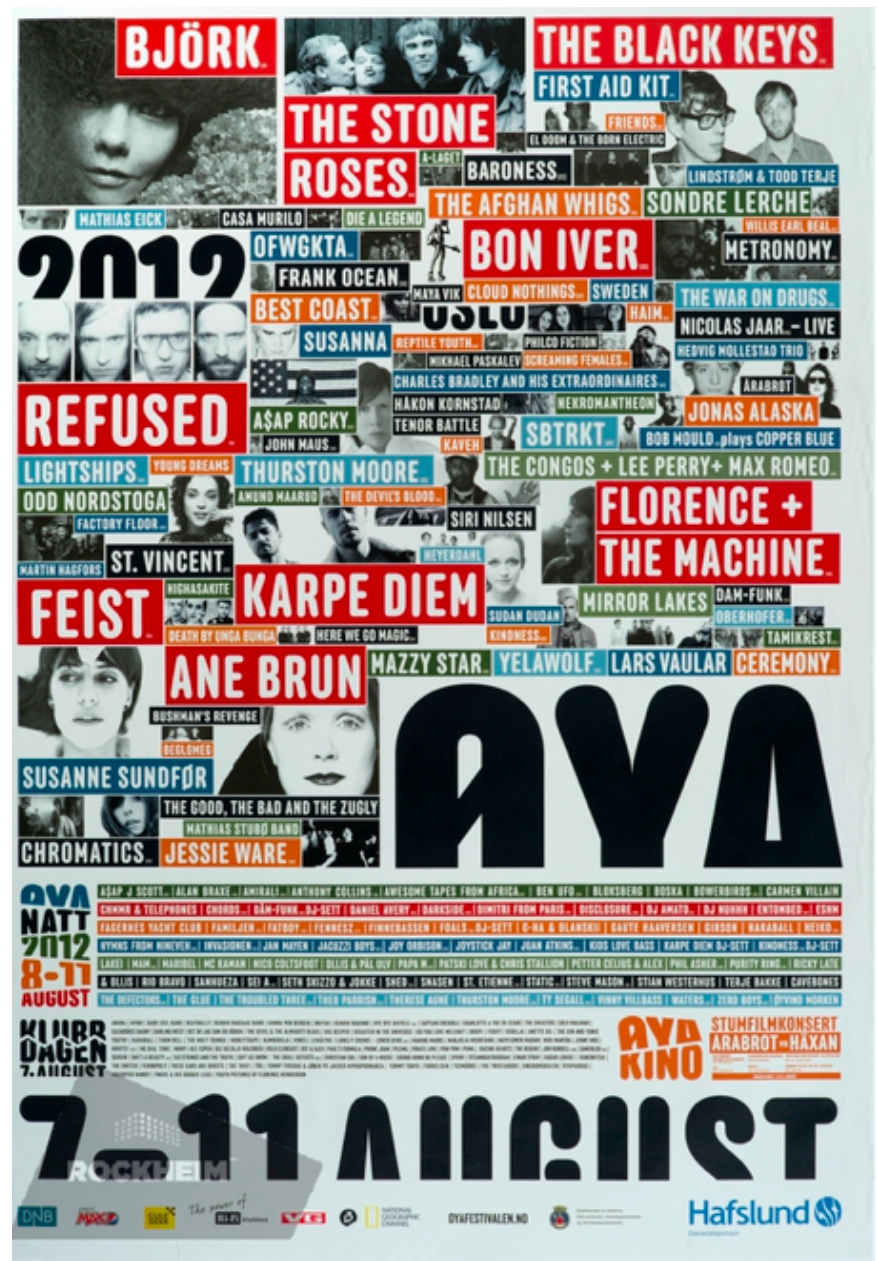

Figure 1. Øya 2012 poster.

The artists were grouped as international headliners $(\mathrm{H})$, medium renowned international artists (M) and local artists (L). Artists highlighted in red on the poster are headliners. Artists displayed in fonts at least the size of 'The War on Drugs' and 'ASAP Rocky' were categorised as medium artists. Because there were relatively few local artists, we decided to work with a single category of local artists (L). An overview of artists in the different segments is provided in table $1 .{ }^{4}$

\footnotetext{
${ }^{4}$ Two medium-sized international artists (The Afghan Whigs and OFWGKTA) lacked artist IDs in the Wimp data and are not part of the present analysis of streaming data.
} 


\begin{tabular}{ll}
$\mathrm{H}(\mathrm{N}=7)$ & $\mathrm{M}(\mathrm{N}=19)$ \\
\hline BJÖRK & A $\$$ AP ROCKY \\
\hline BON IVER & BARONESS \\
\hline FEIST & BEST COAST \\
FLORENCE + THE MACHINE & CEREMONY \\
\hline REFUSED & CHROMATICS \\
\hline THE BLACK KEYS & FIRST AID KIT \\
\hline THE STONE ROSES & FRANK OCEAN \\
\hline L (N=9) & JESSIE WARE \\
ANE BRUN & LIGHTSHIPS \\
\hline JONAS ALASKA & MAZZY STAR \\
\hline KARPE DIEM & METRONOMY \\
\hline LARS VAULAR & MIRROR LAKES \\
\hline ODD NORDSTOGA & NICOLAS JAAR - LIVE IN CONCERT \\
\hline SIRI NILSEN & SBTRKT \\
\hline SONDRE LERCHE & ST. VINCENT \\
\hline SUSANNA & THE CONGOS \\
\hline SUSANNE SUNDFØR & THE WAR ON DRUGS \\
\hline & THURSTON MOORE \\
\hline
\end{tabular}

Table 1. Overview of the headlining $(\mathrm{H})$, medium renowned international $(\mathrm{M})$ and local (L) Øya 2012 artists included in this study.

\section{Streaming data}

We relied on anonymised data related to the streaming of the Øya festival artists in Wimp in 2012, which was available through the Clouds and Concerts project. Data encompassed all of the activity by all of the users in Norway over seven weeks surrounding the festival week. (For further details regarding the initial preparation and analyses of this data, see Maasø, 2016.)

We organised the data as a time series of streams per day that started ten days before the concert day and ended ten days after it (for a total of twenty-one days). The time series were normalised in two ways: (1) by calculating streaming for each day as a share of the average streaming (arithmetic mean) over the whole period, and (2) by calculating streaming for each day as a share of the streaming on the concert day for each artist. The latter method enables the effective comparison of post-concert streaming statistics, as it gives each artist the same starting point (the concert day). For all but a few of the artists, streaming peaked on the concert day. Plots of the time series of artist streaming for each respective concert day are presented in the results 
section. The mean of means for the three artist segments (H, M and L) was then calculated for each day in the twenty-one-day period, and the time series for each segment was plotted. Artists were also coded by concert day (artists that played on day 1 were coded as 1 , on day 2 as 2 , and so on). In order to investigate whether the level of streaming increased after the concert, T-tests of differences between average streaming pre-event (ten days preceding the concert day) and post-event (ten days following the concert day) were conducted for all artists, as well as for each artist segment individually. All statistical analysis were performed in StatPlus:mac, version 6, (AnalystSoft Inc.). P-values are reported significant at $\mathrm{p}<0.05$.

\section{Twitter data}

Data was collected via Hoot Suite (https://hootsuite.com/), a provider of social media management that can be used to collect tweets based on self-selected search words. We entered the relevant search words in Hoot Suite prior to the festival, and all tweets including words that contained Øya, øya, Oya or oya were harvested. After the festival we received text files from Hoot Suite with all of the tweets mentioning these words, including both the actual content of the tweets and the metadata accompanying the tweets. The data consisted of 3488 tweets from 2167 unique users. Duplicates were deleted and the tweets were sorted chronologically on artists/bands. The time series for each artist was normalised by calculating tweets per day as a share of the average (arithmetic mean) for the whole period, again starting ten days before the concert day and ending ten days after it (total of twenty-one days). Plots of the time series of mean of means of tweets for all of the artists sorted on each concert day (tweets mentioning the artists playing on days 1,2, 3 and 4, respectively) are presented in the results section. The tweets were also grouped in three-hour windows (0-3, 3-6 and so on). A plot of the three-hour window including the concert $(\mathrm{C}) \pm$ fifteen hours ( \pm five time windows) for the total number of tweets (all artists summarised) is shown in the results section.

We then sorted the tweets into five categories based on manual inspection of the content of the tweets: expectation, evaluation, artist/industry, miscellaneous (misc.) and retweets (RT). Artist/industry tweets were separated from 'ordinary Twitter users' because their twitter-activity could be biased by economic interests. The miscellaneous category comprised tweets such as 
comments on concert cancellations, announcement of one's presence ('I am here'), comments on one's absence ('I wish I were there') and Tweets related to other events.

\section{Measures of positive Twitter evaluation and post-concert streaming}

As a measure of success for a festival concert performance, we used that performance's share of evaluation tweets. Artists with less than twenty tweets were excluded from the analysis, which amounted to the lowest quartile (up to 25 percent) of all headliners, medium international and local artists. The share of evaluation tweets (out of all tweets) was then calculated for each artist separately, and the artists were plotted from lowest to highest share. Because of large differences in the share of retweets (RT) (see figure 2), we decided to exclude retweets from all tweets.

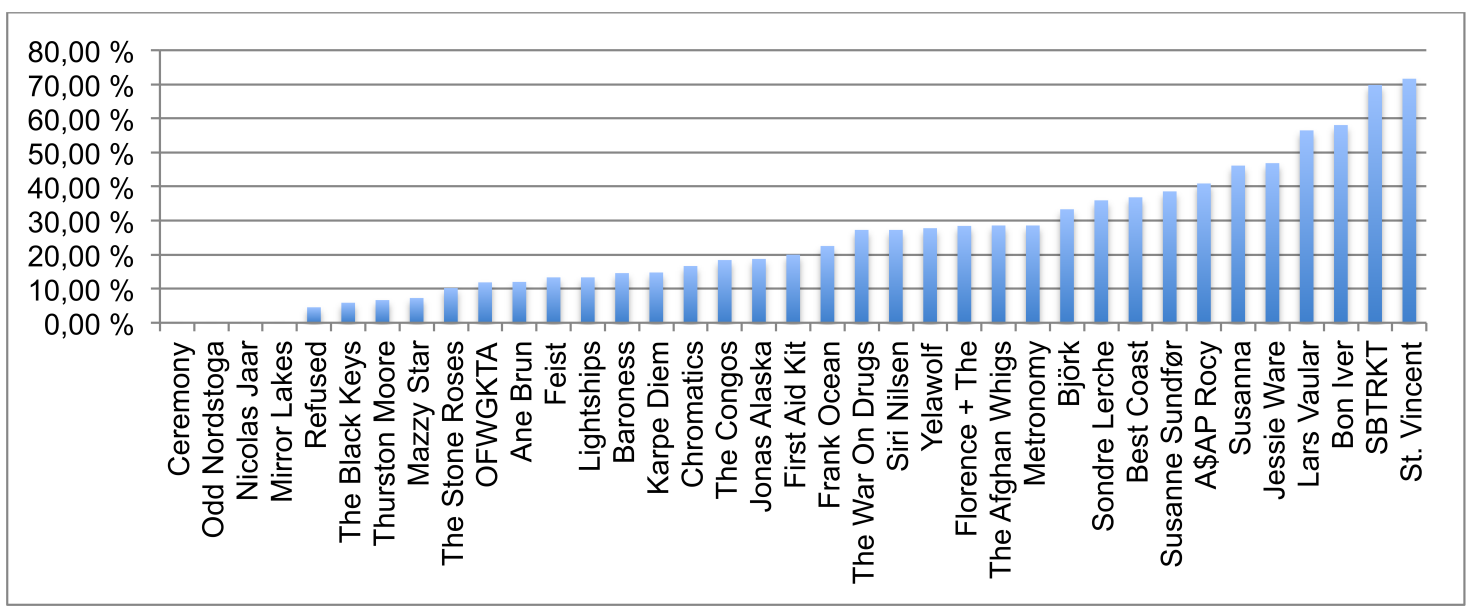

Figure 2. Share of retweets of total of tweets for each artist.

We then investigated whether the positive evaluation of the festival concert had an effect on streaming after the concert (post-event streaming) as opposed to before the concert (pre-event streaming). The evaluation-tweet share of total tweets (RT excluded) for each artist was used to divide the artists into two overall groups: artists with evaluation-tweet shares above (HIGH) and below (LOW) the median for all artists. Plots of normalised time series of streaming for all artists, as well as artist segments, belonging to the high and low groups are presented in the results section. We then conducted statistical tests to see whether evaluation-tweet share influenced streaming after the concert. 


\section{Results}

In what follows, we begin by presenting the general patterns over time for streaming and tweeting during the festival period. Then we look at streaming results for the different artist segments, the results of the content analysis of the tweets, and, finally, the relationship between positive evaluation of the concert on Twitter and post-event streaming.

\section{Time distribution of tweets and streams}

The results indicate distinctly different patterns for festival-related tweets and streams (see figures 3 and 4).

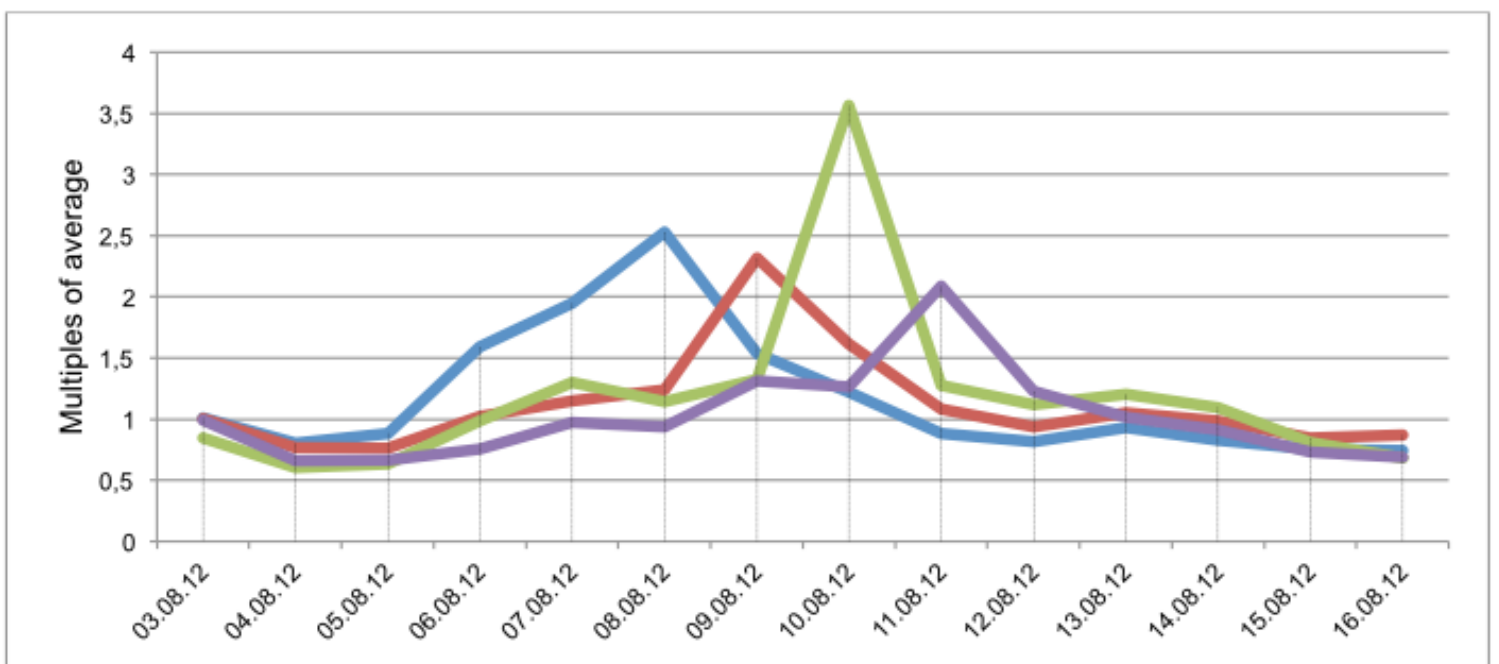

Figure 3. Streaming sorted by concert day. Number of streams per day divided on average of concert day \pm 10 days. 


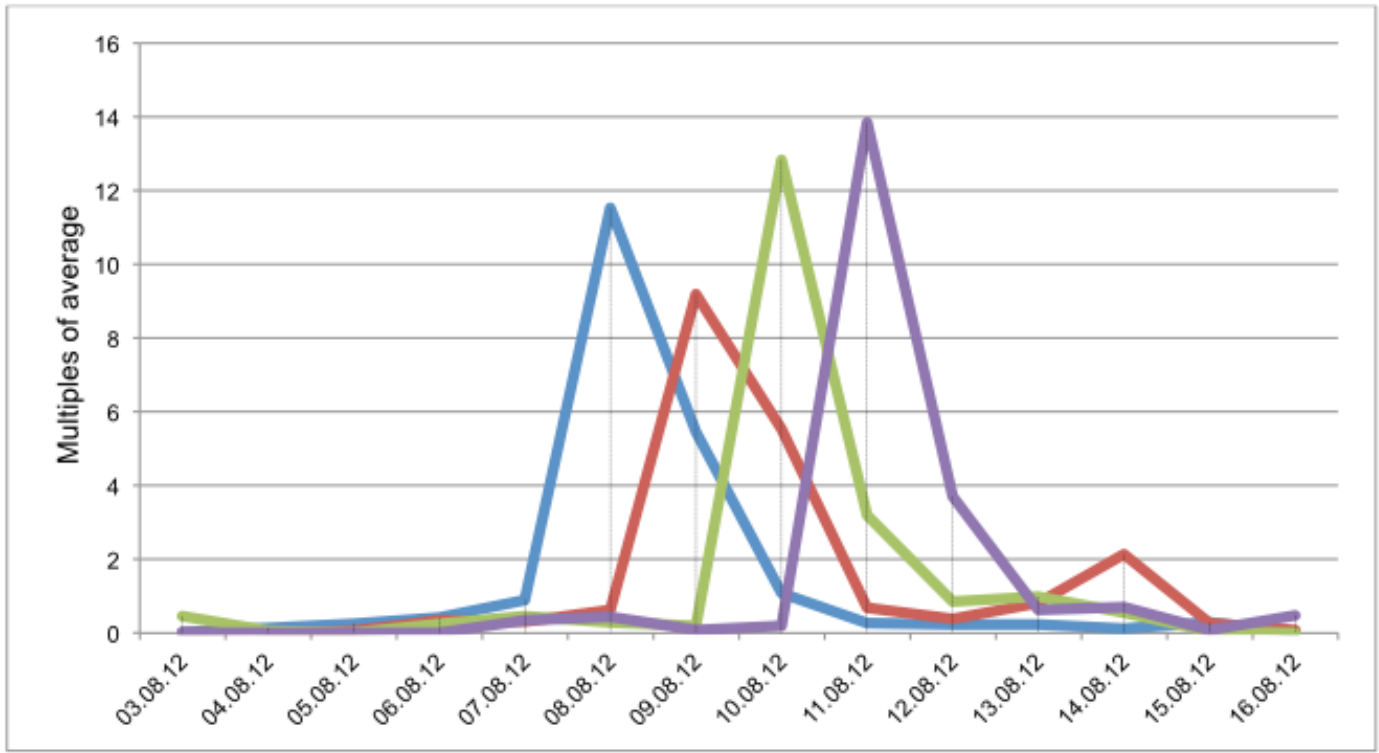

Figure 4. Tweeting sorted by concert day. Number of streams per day divided on average of concert day \pm 10 days.

The tweet patterns display extreme peaks - that is, between ten and fourteen times the average of the whole period - on the day of the concert. Closer inspection of the concert day reveals that most of the tweeting actually happens during and immediately after the concert itself (see figure 5).

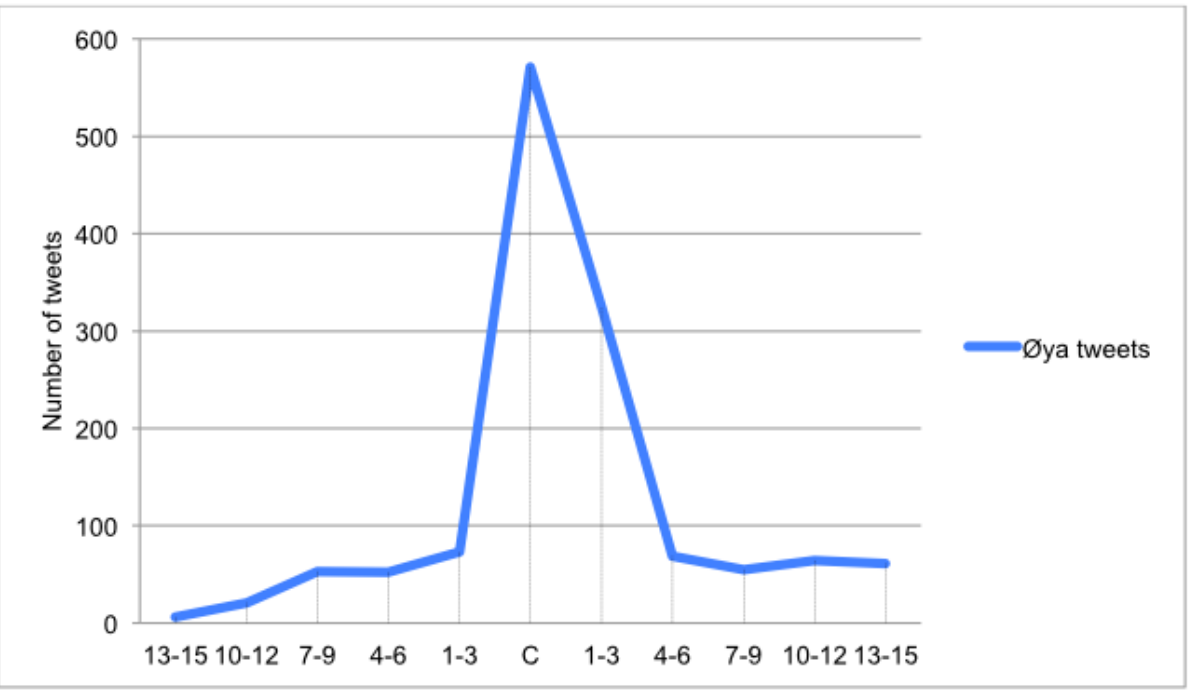

Figure 5. Distribution of Øya tweets over time. $\mathrm{C}=$ the three-hour time window including the concert. X-axis shows hours before (left of C) or after (right of $\mathrm{C}$ ) the concert. 
There is little pre-event tweeting, and the Twitter tail after the concert is also very short (one day). This means that most of the Twitter activity related to the festival takes place on the concert day and the day after. The streaming patterns also display marked peaks on the day of the concert. However, here there is a longer buildup to the event and a longer tail after it. Interestingly, as well, pre-event listening is particularly high for the first festival day in relation to the others.

In sum, Twitter activity showed a marked peak during and immediately after the concert, whereas festival-related streaming takes place over a longer period, showing significant levels of pre- and post-event listening.

\section{Streaming before and after the festival concert for different segments of artists}

The plot in figure 6 reveals that the streaming of local acts (L) does not peak to the same degree on the concert day as it does for headliners $(\mathrm{H})$ and medium international acts $(\mathrm{M})$.

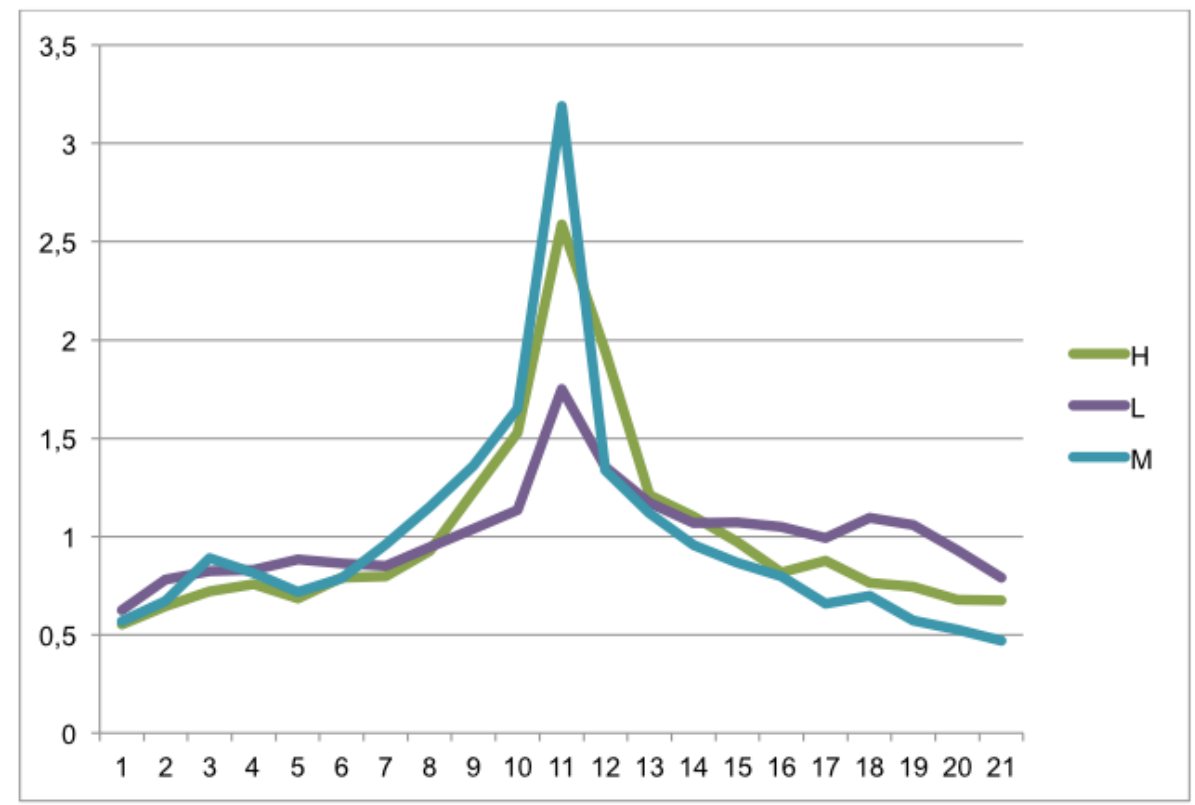

Figure 6. Streaming / time for concert day \pm 10 days. Concert day $=$ day 11. (Average of concert day \pm 10 days $=1$ ). End of streaming tail defined as the point when the curve crosses averagethat is, the value 1 on the y-axis. (Outliers removed for Jessie Ware [album release] and SBTRKT [single release]). 
However, if compared to the level of streaming on the festival day, the festival effect lasts longer for local artists - the local-artist streaming tail (the end of which is defined as crossing of average for concert day \pm ten days) is nine days, whereas for headliners and medium-sized artists, it is four and two days, respectively (see figure 7).

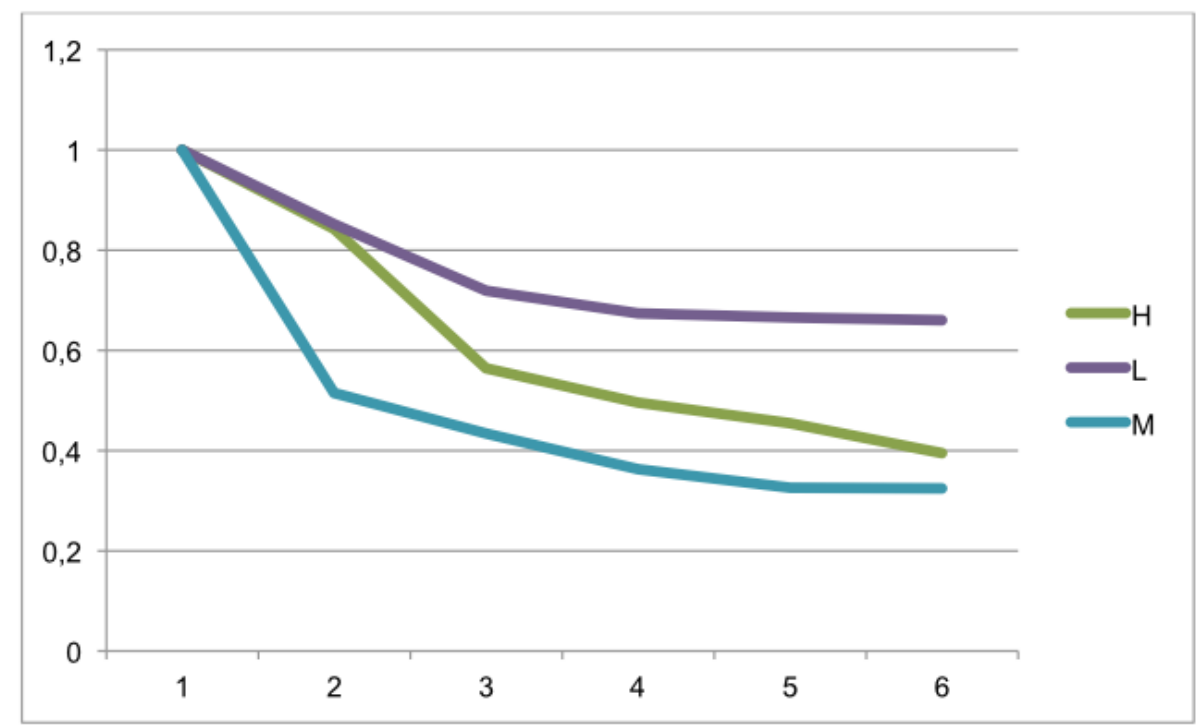

Figure 7. Streaming / time for all headlining (H), medium international (M) and local (L) artists. Day $1=$ concert day. Number of streams per day divided by streams on concert day.

Streaming in the ten-day period following the concert was on average almost the same as the ten days preceding the concerts for all artists taken together (descriptive statistics are provided in table 2 below).

\begin{tabular}{l|c|c|c|c|c|c|c|c|c|c|} 
& \multicolumn{4}{|c|}{} & \multicolumn{4}{c|}{ Post-event streaming } \\
\hline & \multicolumn{4}{|c|}{ Pre-event streaming } & \multicolumn{4}{c|}{} \\
\hline & Avg & SD & Min & Max & Avg & SD & Min & Max & $N$ \\
\hline All artists & 0,9174 & 0,26 & 0,5787 & 1,4941 & 0,9040 & 0,25 & 0,5971 & 1,4628 & 33 \\
\hline Headliners (H) & 0,8631 & 0,28 & 0,5512 & 1,5276 & 0,9782 & 0,36 & 0,6755 & 1,9433 & 7 \\
\hline Medium international artists (M)* & 0,9568 & 0,32 & 0,5674 & 1,6513 & 0,8002 & 0,26 & 0,4694 & 1,3381 & 17 \\
\hline Local artists (L) & 0,8777 & 0,13 & 0,6238 & 1,1362 & 1,0578 & 0,14 & 0,7917 & 1,3522 & 9
\end{tabular}

Table 2. Descriptive statistics of average pre- and post-event streaming (ten-day periods) for all artists and different segments of artists. Each artist's streaming normalised on average of concert day \pm ten days (average $=1$ ). 
Looking at the numbers for different artist segments, we see that headliners have a small increase, local artists have a substantial increase and medium international artists have a small decrease from pre- to post-event streaming. T-tests were conducted to check the solidity of the differences. The results show that the increase for local artists is significant $(\mathrm{t}(18)=2.806, \mathrm{p}=0.012$, twotailed). No significant differences were found for headliners, medium international artists or all artists taken together.

\section{Content analyses of tweets}

Content analysis reveals that evaluation tweets (27 percent) and retweets (32 percent) are the dominant categories. If we exclude retweets, the numbers reveal that almost 40 percent of the remaining - that is, original — tweets are evaluation tweets (see figure 8). A closer inspection of the evaluation tweets also shows that evaluation tweets are positive, with only a few exceptions. The share of expectation tweets is rather low. There are also surprisingly few tweets among the original tweets that are generated by the artists and the music industry. The miscellaneous category, which includes, for example, 'I am here' tweets, is expansive.

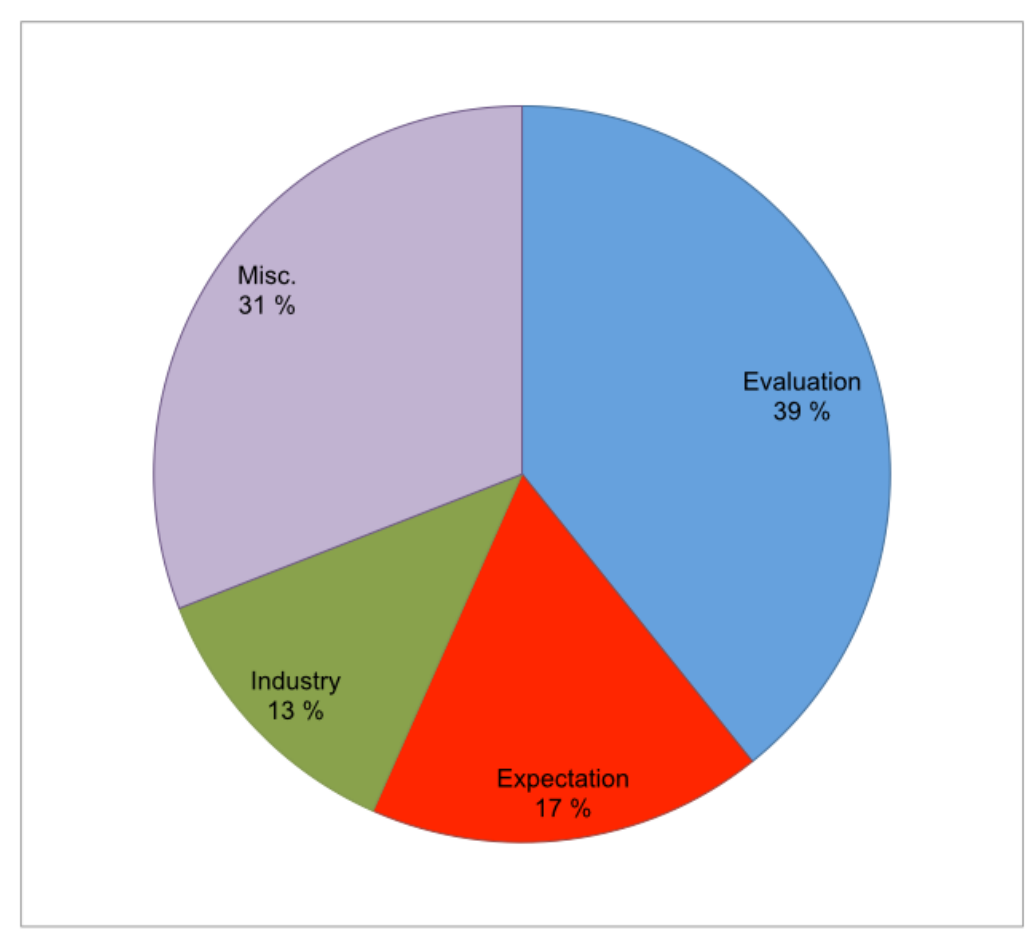

Figure 8. Tweets sorted into content categories (retweets excluded). 
Regarding the retweet category (RT), we see that industry tweets amount to 76 percent here, which means that the few original industry tweets generate a lot of retweeting. This is probably because artists and industry people generally have much larger followings than the rest of us. Other notable categories include evaluation (12 percent), miscellaneous (9 percent) and expectation (3 percent).

Plots of time series for the total number of tweets for the ten artists with the most tweets (see figure 9) confirm that Twitter is a here-and-now medium.

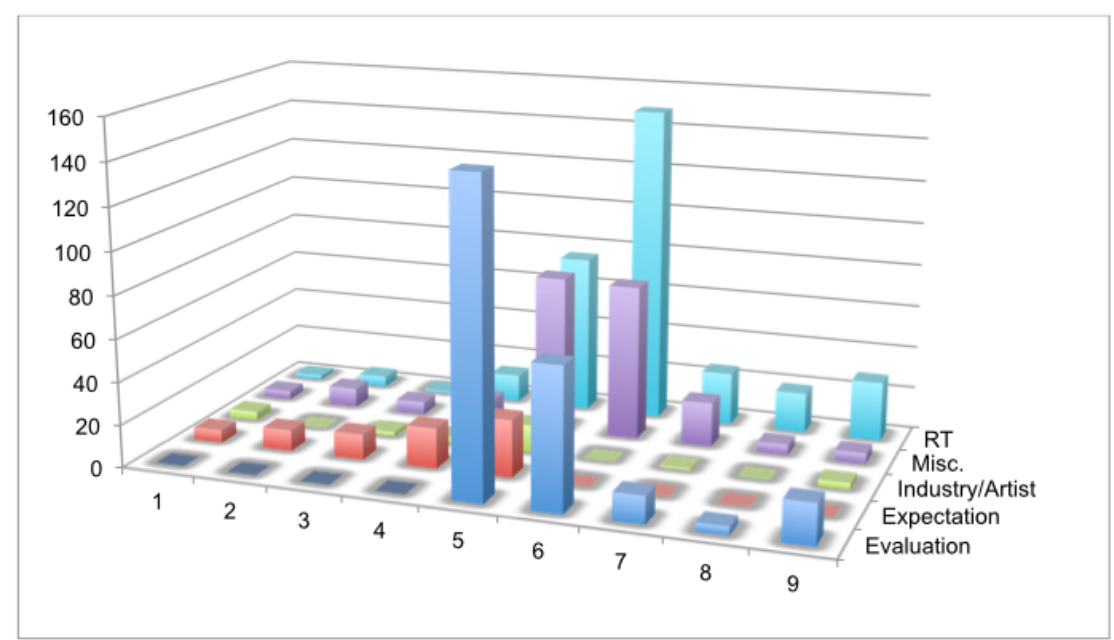

Figure 9. Distribution of Øya tweets for the ten artists with the most tweets, sorted by content. Concert \pm 12 hours; 5 = the three-hour time window including the concert. X-axis shows hours before (left of 5) or after (right of 5) the concert.

Evaluation clearly peaks in the time window that includes the concert. Retweeting starts in the time window of the concert but peaks in the hours following the concert. A trend towards preevent activity (expectation tweets) emerges, though the share is low in relation to evaluation and retweets.

\section{Twitter evaluation and post-event streaming}

Plots of streaming during the festival period show that artists with a high share of evaluation tweets - that is, those residing above the median share of evaluation tweets (HIGH) - enjoy a 
more gradual decrease in post-event streaming than those whose share is below the median share (LOW)—-see figure 10.

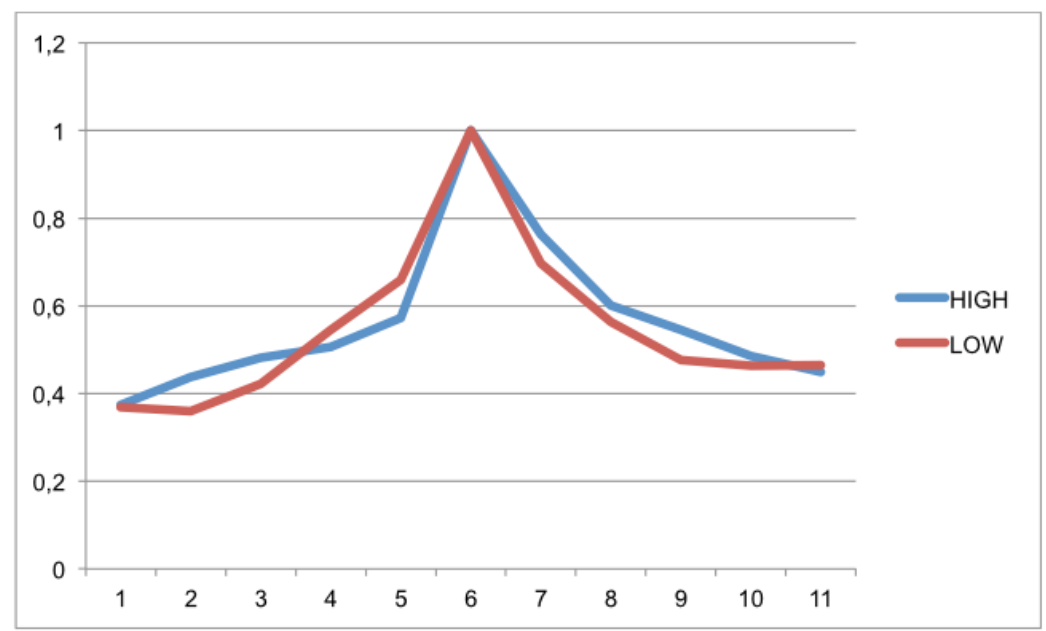

Figure 10. Streaming / time. Day $6=$ concert day. Number of streams per day divided by streams on concert day. $\mathrm{HIGH}=$ the upper 50 percent of artists, ranked from lowest to highest share of evaluation tweets. $\mathrm{LOW}=$ the lower 50 percent.

The increase in streaming from the ten days preceding the concert (pre-event streaming) to the ten days following it (post-event streaming) is also on average higher for the HIGH group (8 percent of streaming on concert day) than for the LOW group (4 percent of streaming on concert day), but none of these differences are statistically significant. Descriptive statistics are provided in table 3 , below.

\begin{tabular}{l|c|c|c|c|c|c|c|c|c|}
\multirow{2}{*}{ Artist segment } & \multicolumn{4}{|c|}{ Pre-event streaming } & \multicolumn{4}{c|}{ Post-event streaming } & \\
& Avg & SD & Min & Max & Avg & SD & Min & Max & $N$ \\
\hline High & 0,4112 & 0,08 & 0,2922 & 0,5730 & 0,4877 & 0,12 & 0,3451 & 0,7632 & 13 \\
\hline Low & 0,4074 & 0,11 & 0,2721 & 0,6596 & 0,4661 & 0,10 & 0,3238 & 0,6754 & 13 \\
\hline All artists & 0,4095 & 0,09 & 0,2826 & 0,6147 & 0,4774 & 0,11 & 0,3352 & 0,7315 & 26
\end{tabular}

Table 3. Descriptive statistics of pre- and post-event streaming (ten-day periods) for artists above (high) and below (low) the median share of evaluation tweets (streaming on concert day $=1$ ).

When we compare the HIGH and LOW streaming tails for the different artist segments (H-HIGH vs. H-LOW, M-HIGH vs. M-LOW, and L-HIGH vs. L-LOW) in the plot in figure 11, 
we see that the difference is particularly salient for local artists - that is, the streaming tail for L$\mathrm{HIGH}$ is substantially higher and longer than it is for L-LOW. This same trend is also marginally present for the headliners (H-HIGH versus H-LOW), whereas for medium-sized artists, the curves for HIGH and LOW follow each other closely. Because the number of artists in some of these groups is extremely small-L-HIGH, for example, consists of only three artists-no statistical tests were conducted on these comparisons.

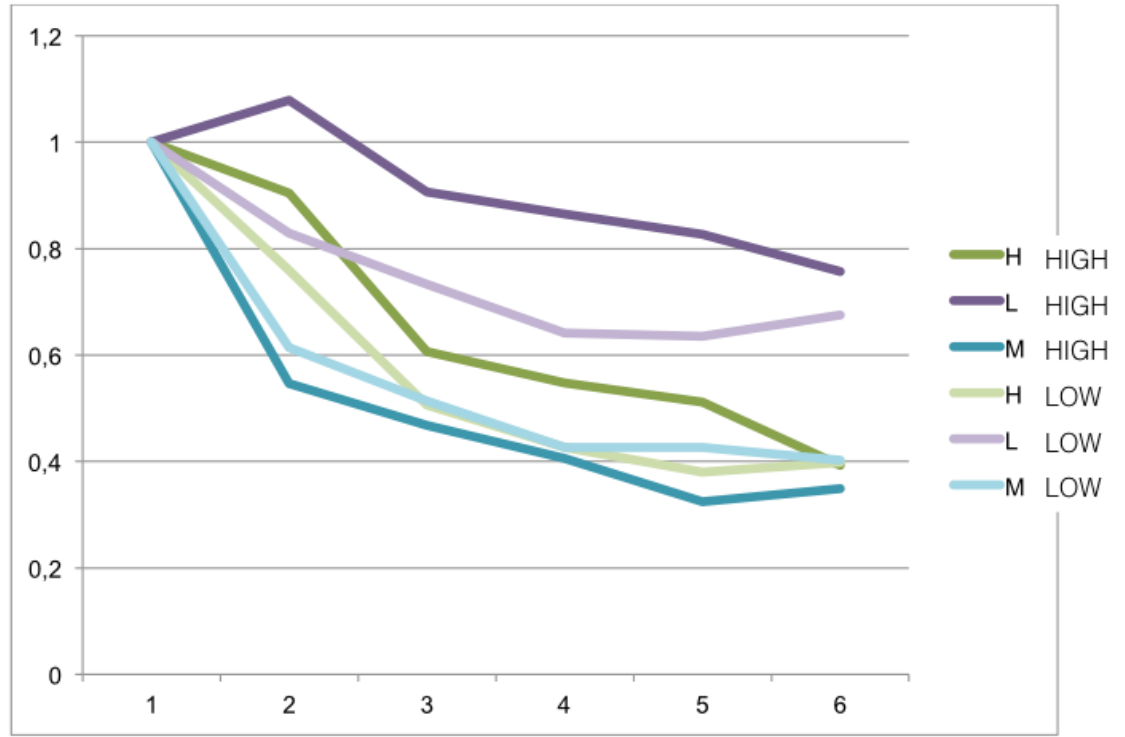

Figure 11. Streaming / time. Day $1=$ concert day. Number of streams per day divided by streams on concert day. $\mathrm{H}=$ headliner, $\mathrm{M}=$ medium international act, $\mathrm{L}=$ local act. Dark color = share of evaluation tweets above median. Light color $=$ share of evaluation tweets below median.

Even though the results must be treated with caution due to the low number of artists in each category and the lack of statistically significant results, the Øya 2012 artists that have a high share of evaluation tweets (above median) have a longer streaming tail. On average they also have a higher level of post-event streaming relative to streaming on the concert day than those with a low share of evaluation tweets. This tendency is particularly salient for local artists. 


\section{Discussion}

Streaming before and after the festival concert for different segments of artists

The time distribution for streaming was expected, because our study is based on parts of the data set used by Maasø (2016), which indicated a clear peak in the streaming of festival artists during the festival week. Maasø reported an approximately 40 percent increase in streaming in the average of total streams per week in the seven weeks surrounding the festival week, compared to two control weeks early in the summer. Our results give a more detailed day-to-day picture of the festival effect by comparing two different ten-day periods - that is, pre- and post-event streaming - within the seven weeks surrounding the festival. When we look at all of the artists together, pre-event streaming builds up to a clear peak on the concert day, to be followed by postevent streaming at about the same level as the pre-event streaming.

When we analyse the data for each artist segment separately, we find that local artists are the only segment with a significant increase from pre- to post-event streaming. For the medium international artists and headliners, there is no significant difference between pre- and post-event listening. One might have expected an increase in streaming for the headliners, given the apparatus surrounding international artists at that level and the ways in which management and the record company probably used the occasion that a festival represents to direct attention to the artist in the territory of the festival. This possibility is not reflected in our analysis, however, though it may be reflected in Maasø's. In contrast to the results presented in this article, there is no normalisation of streaming data for the different artists in Maasø's study, which means that artists with high streaming levels, such as headliners, influence the results accordingly. On the other hand, we report only normalised data, which means that each artist is equally weighted in the comparison. Moreover, by limiting our time period to the ten days immediately preceding and succeeding the concert, we also focus on the effect of the actual concert as such, whereas Maasø captures to a greater extent the general effect of the exposure derived from being part of a festival program.

One might also have expected that medium international artists and local artists would not have the resources to use the occasion of a festival to attract attention in the same way that international headliners would. Unsurprisingly, we see very little increase in post-event streaming for medium international artists. Local artists, on the other hand, seem to benefit greatly from a 
festival such as Øya, likely because it is a huge local event (see, for example, Maasø, 2016). Its local artists are likely to attract extra attention from the local audience, even (or especially) in the context of popular international acts. A festival such as Øya can thus be characterised as a meeting of global and local culture, and its local engagement, including its volunteers, the media attention and the network effects within the local audience, ${ }^{5}$ fuels the exposure and streaming of its local artists.

\section{Twitter: monitoring the festival public}

The time-distribution profiles for Twitter use, as mentioned above, indicate that Twitter is a 'here-and-now' medium, in accordance with previous research into Twitter use in political campaigns (Larsson and Moe, 2012). There is little research into Twitter use during concerts, but our findings resonate with previous studies by Bennett $(2012,2014)$ and Jamison-Powell and colleagues (2014), as well as unpublished studies of tweeting at Øya 2011 (Maasø, 2012) and the by:Larm festival in 2011 (Sandnes et al., 2011). Both found that 'here-and-now' tweets were predominant, and, moreover, that tweets were typically instant reactions to the live concert event or its atmosphere. The by:Larm study concluded that many people used Twitter as a means of sharing concert experiences during by:Larm, and that they were most concerned with evaluating and sharing what they experienced with others. In short, both this study and previous research point towards Twitter as a medium in which content is meant to be exploited in real time (that is, during the event) in relation to what is happening at that moment. We also found that Twitter was used, first and foremost, to communicate positive evaluations of the concert, which is in line with research describing the cultural phenomenon of the festival as an occasion for positive, collective celebration (see, for example, Gibson and Connell, 2012; McKay, 2015).

As both Bennett and colleagues (2014) and McKay (2015) point out, a festival is a social gathering that creates a shared identity and belonging. From this perspective, Twitter and other social media may be seen as a mediated aspect of this ad-hoc mini-public (Baym, 2013). Put differently, the Twitter community surrounding a festival like Øya is an ad-hoc mediatised public

\footnotetext{
${ }^{5}$ Maasø (2016), for example, reports that during the four festival days, there were, on average, 131 percent more festival streams by users in the city (less than ten kilometres from the venue) than there were festival streams by users living between fifty and one hundred kilometres away.
} 
gathering to discuss the 'state of the art' within the genre culture of the festival. As Stone (2009) points out, a festival supplies its audience with an update on new artists/bands and trends, and Twitter can be seen as a forum where one evaluates and discusses — in short, consolidates - the state of that art. Because it is mediated, as well, this ad-hoc festival public also encompasses those not actually present at the festival. In this way, Twitter communication evokes the traditional media, in that opinion leaders can inform a larger audience, both there and not there, about current trends and sensibilities involving the concert at hand.

\section{Positive evaluation and streaming tail}

Artists with a high share of evaluation tweets generally have a higher level of post-event streaming than artists with a below-median share, indicating that the quality of the concert is relevant to post-event listening with streaming services. A very interesting finding is that local artists who are positively evaluated on Twitter (L-HIGH) have a markedly higher and longer streaming tail than any of the other artist segments. As mentioned above, however, these trends have to be treated with caution, because the number of artists in some of these groups was very small. The L-HIGH category, for example, consisted of only three artists, though media coverage confirms that these artists delivered some of the most acclaimed concerts at Øya in 2012. Of course, the great increase in post-event listening to these artists may also be due to a particularly low level of pre-event listening. Interestingly, all three of these artists are female, and in the future we would like to investigate the extent to which there are gender differences in post-event streaming patterns.

Generally, this result indicates that high-quality live performances are probably a very effective means of generating an increase in streaming both directly and indirectly as a consequence of a positive evaluation in the mediated ad-hoc public gatherings that are associated with the live event.

\section{Conclusion}

By combining data on social media usage with online music consumption statistics, we have been able to demonstrate the emergence of a close relationship between the domains of live and recorded music in our time. First of all, this research validates the assumption that a festival 
performance generates exposure via micro-blogging (Twitter) and enhances listening to musicstreaming services (Wimp). Particularly interesting is the fact that local artists in particular seem to benefit from this interaction between the live and the recorded; our findings indicate that the live event is a unique opportunity for exposure for local artists, who otherwise tend to drown in an expanding sea of recordings. This is an interesting contribution to ongoing discussions regarding the impact of international headliners and hits upon contemporary music culture (and local subcultures). Our study also foregrounds the challenges faced by medium international artists who seek an audience by touring within the growing international arena of music festivals but struggle to connect with the local audiences. However, a key point from our study is encouraging to all artist groups - what actually happens on stage and in the moment of the event still seems to be very significant, as is reflected in the indications of a positive effect of a good Twitter evaluation on post-event streaming (the streaming tail). This shows that the quality of the live experience most likely has consequences for the consumption of recorded music as well.

At a more general level, the audience's festival-related activities on streaming platforms and in social media illustrate the ways in which a live event now extends far beyond the here and now of the actual concert or festival venue. Music and media are deeply intermingled when the audience uses their mobile phones to prepare and process, document, and communicate the event on online platforms before, during and after it (Kjus and Danielsen, 2014). The contemporary live music event is thus to an increasing extent a blend of 'here and now' and mediated forms of expression and communication — both off and on stage ${ }^{6}$ - and there is no reason to believe that this intermingling of live and mediated forms will decrease in the years to come.

In future research it would be interesting to look deeper into the common characteristics of the live music performances that trigger extended media engagement using qualitative methods. The response of the audience also requires further research, in particular as to patterns in the reception and appreciation of artists associated with gender, genre communities and social groups. This will be a further step towards identifying what forms of mediated social publicness that arises within (and around) live festival events.

\footnotetext{
${ }^{6}$ Technological tools and processes of pre-production are today ubiquitous in contemporary live-music production (Knowles and Hewitt, 2012; Kjus and Danielsen, forthcoming) with the consequence that even on stage the live music event is now extended in time and space (Danielsen and Helseth, 2016).
} 


\section{References}

Baumol W and Bowen W (1966) Performing Arts, the Economic Dilemma: A study of problems common to theater, opera, music, and dance. New York: Twentieth Century Fund.

Baym N (2013) The perils and pleasures of tweeting with fans. In: Weller K et al. (eds) Twitter and Society. New York: Peter Lang, pp. 221-236.

Bennett L (2012) Patterns of listening through social media: online fan engagement with the live music experience. Social Semiotics 22(5), 545-557.

Bennett L (2014) Texting and tweeting at live music concerts: Flow, fandom and connection with other audiences through mobile phone technology. In: Burland K and Pitts PS (eds) Coughing and Clapping: Investigating audience experience. Farnham: Ashgate, pp. 89100.

Bennett A, Taylor J and Woodward I (2014) Introduction. In: Bennett A, Taylor J and Woodward I (eds) The Festivalization of Culture. Farnham: Ashgate, chapter 1.

Bowen H E and Daniels M J (2005) Does the music matter? Motivations for attending a music festival. Event Management 9(3): 155-164.

Brennan M and Webster E (2010) The UK festival market report. UK 2010 Festival Awards Programme, pp. 25-39. Available at: http://livemusicexchange.org/wpcontent/uploads/Festival-Awards-2010-Report-FINAL.pdf (accessed 26 May 2016).

Bruns A and Moe H (2013) Structural layers of communication on Twitter. In: Weller K et al. (eds) Twitter and Society. New York: Peter Lang, pp. 15-28.

Comte Bureau (2012). Øya Audience Survey: Report for the Øya festival. Oslo.

Danielsen A and Helseth I (2016) Mediated immediacy: The relationship between auditory and visual dimensions of live performance in contemporary technology-based popular music. Rock Music Studies 3(1): 24-40.

Fonarow W (2006) Empire of Dirt: The aesthetics and rituals of British indie music. Middletown, CT: Wesleyan University Press.

Frith S (1987) Towards an aesthetic of popular music. In: Leppert R and McClary S (eds) Music and Society. Cambridge: Cambridge University Press, pp. 133-149.

Frith S (2007) Live music matters. Scottish Music Review 1(1): 1-17. 
Gibson C and Conell J (2012) Music Festivals and Regional Development in Australia. Farnham: Ashgate.

Hesmondhalgh D (2013) Why Music Matters. Hoboken, NJ: John Wiley and Sons.

Hitzler R, Kirchner B and Pahl J (2013) Event-konzepte: Juvenlie Inszenierungen zwischen Integration und Distinktion. Zeitschrift für Erziehungswissenschaft 16: 143-158.

IFPI (2015). IFPI Digital music report: Charting the path to sustainable growth. Report, IFPI. Available at: http://www.riaa.com/wp-content/uploads/2015/09/Digital-Music-Report2015.pdf (accessed 26 May 2016).

IFPI (2016). Global music report 2016: State of the industry. Report, IFPI. Available at: http://www.ifpi.org/downloads/GMR2016.pdf (accessed 26 May 2016).

IFPI Norge (2013). Digitalt vs. fysisk i 2012. Report, IFPI Norway. Available at: http://www.ifpi.no/flere-nyheter/item/38-digitalt-vs-fysisk-i-2012 (accessed 26 May 2016).

IFPI Norge (2015). Musikkåret 2014: IFPI Norges årsrapport. Report, IFPI Norway. Available at: https://dl.dropboxusercontent.com/u/26234926/Årsrapport_Ifpi_2014_low.pdf (accessed 26 May 2016).

ITU Statistics (2016). Key ICT indicators for developed and developing countries and the world. Report, International Telecommunication Union. Available at: http://www.itu.int/en/ITUD/Statistics/Pages/stat/default.aspx_(accessed 3 June 2016).

Jamison-Powell S, Bennett L, Mahoney J, and Lawson S (2014). Understanding in-situ social media use at music festivals. In Proceedings of the companion publication of the 17th ACM conference on Computer supported cooperative work \& social computing, pp. 177-180. Baltimore, MD: ACM.

Jenkins H (2006) Convergence Culture: Where old and new media collide. New York: New York University Press.

Kavli H and Sjøvold JM (2015). Musikk i tall 2014. Report for Arts Council Norway. Available at: http://www.kulturradet.no/documents/10157/bd41abad-ef43-43f8-914f-97a1 1b0b5e20 (accessed 26 May 2016).

Kjus Y and Danielsen A (2014) Live islands in the sea of recordings: The music experience of visitors at the Øya festival. Popular Music and Society 37(5): 660-679. 
Kjus Y and Danielsen A (forthcoming 2016) Live mediation: Performing concerts using studio technology. Popular Music 35(3).

Knowles J and Hewitt D (2012) Performance recordivity: Studio music in a live context. Journal on the Art of Record Production 6. Available at: http://arpjournal.com/performancerecordivity-studio-music-in-a-live-context/ (accessed 16 June 2016).

Larsson AO and Moe H (2012) Studying political microblogging: Twitter users in the 2010 Swedish election campaign. New Media and Society 14(5): 729-747.

Maasø A (2012) Expanding and enhancing the 'live' music experience: Analyzing streaming and social media behavior before, during and after a festival. Paper given at Ross Priory Seminar on Broadcast Talk 2012.

Maasø A (2016). Music streaming, festivals, and the eventization of music. Popular Music and Society, 1-22. http://doi.org/10.1080/03007766.2016.1231001

McKay G (2015) Introduction. In: McKay G (ed) The Pop Festival: History, music, media, culture. London and Oxford: Bloomsbury, chapter 1.

Mortimer JH, Nosko C and Sorensen A (2012) Supply responses to digital distribution: Recorded music and live performances. Information Economics and Policy 24(1): 3-14.

Robinson R (2015) Music Festivals and the Politics of Participation. Farnham: Ashgate.

Sandnes A et al. (2011) Den nye Twitter-festivalen \#bylarm: En medievitenskapelig undersøkelse av bruken av Twitter under by:Larm 2011. Bachelor's thesis, University of Oslo.

Sanjek R and Sanjek D (1991) The American Popular Music Business in the 20th Century. New York: Oxford University Press.

Statistics Norway (2016). ICT usage in households. Report, Statistics Norway. Available at: https://www.ssb.no/statistikkbanken/selectvarval/saveselections.asp (accessed 3 June 2016).

Steinkellner A (ed) (2015) Kulturstatistikk 2014. Report, Statistics Norway. Available at: https://www.ssb.no/kultur-og-fritid/artikler-ogpublikasjoner/_attachment/250101?_ts=152cab395e8 (accessed 26 May 2016).

Stone C (2009) The British pop music festival phenomenon. In: Ali-Knight J et al. (eds) International Perspectives of Festivals and Events: Paradigms of analysis. London: Elsevier, pp. 205-224. 
Taule L (ed) (2010) Kulturstatistikk 2009. Report, Statistics Norway. Available at:

https://www.ssb.no/a/publikasjoner/pdf/sa_117/sa_117.pdf (accessed 26 May 2016).

Twitter (2012). Tweet from Twitter.com. Available at:

https://twitter.com/twitter/status/281051652235087872 (accessed 4 June 2016).

Twitter (2016). Company. Twitter. Available at: https://about.twitter.com/company (accessed 26

May 2016).

Vaage OF (2013) Norsk kulturbarometer 2012. Report, Statistics Norway. Oslo: Statistics

Norway.

Wikstrøm P (2013) The Music Industry: Music in the Cloud. 2nd edition. Cambridge: Polity Press.

Ytreberg E (2009) Extended liveness and eventfulness in multi-platform reality formats. New

Media and Society 11(4): 467485.

Aalen I (2015) Sosiale medier. Bergen: Fagbokforlaget. 